\title{
Creating a Body of Knowledge for cartography
}

\author{
David Fairbairn $^{\mathrm{a}}$ \\ ${ }^{a}$ School of Civil Engineering \& Geosciences, Newcastle University, Newcastle upon Tyne, UK; david.fairbairn@newcastle.ac.uk
}

\begin{abstract}
The nature of knowledge is considered, in particular its creation and formalisation, and some of the issues which re-late to disciplinary knowledge in particular. It is suggested that cartography has particular needs addressing its disciplinary boundaries, the role of uncertain and 'troublesome' knowledge in its subject-matter, and the enhancement of its subject-specific knowledge, with more generic supporting material, including skills and attitudes. An overview of Bodies of Knowledge (BoK) in other disciplines has been undertaken, and models of BoK structure, content and usage have been assessed. BoKs in closely related subjects, including civil engineering, GIS and software engineering, give examples of good practice. The paper concentrates on the work done to date to create the cartography BoK, and the adoption of the 'Delphi' method of consultation to develop it. The Delphi method is intended to yield consensus on the scope, content, context and use of the BoK. It is regarded as a rigorous process, iterative (and therefore time consuming), involving questionnaire survey, opinion gathering, discourse analysis, and feedback. The participants are expected to be experts, from a range of different sectors, but 'volunteer amateurs' are also important consultants.
\end{abstract}

Keywords: Curriculum, Professional Development, Knowledge, Body of Knowledge content, Cartographic Practice

\section{Context}

The International Cartographic Association (ICA) Commission on Education \& Training (CET) was approved for the 2015-2019 quadrennial period at the ICA General Assembly in Rio de Janeiro in August 2015. The Com-mission was renewed with several Terms of Reference:

- To work towards the overall aims of ICA as specified in the Statutes, engaging with the International Map Year (IMY) initiative, and disseminating outputs through the International Journal of Cartography and presentations at International Cartographic Conferences (ICCs);

- To promote and deliver workshops (and online, eLearning alternatives), possibly in conjunction with other ICA Commissions

- To maintain a record of educational courses which address cartography at all levels (including ad hoc courses)

- To examine the role of accreditation of educational courses by professional bodies

- To explore the possibilities of developing a Body of Knowledge (BoK) for cartography

There are several reasons for identifying the Body of Knowledge as a priority goal for the Commission. There is a widespread understanding that cartography needs to stake its 'disciplinary territory' (Buchroithner and Gartner, 2013). The success of related fields such as Geographic Information Science in establishing credentials as a discipline, and the way in which the cartographic paradigm is being absorbed into data handling in many other disciplines, ranging from archaeology and computer science, to journalism and geophysics, has led to inevitable confusion in identifying the bounds of our subject. Associated with such vibrancy in related disciplines, there is a belief that cartography needs to promote itself to improve its own low profile this was a major factor in promoting IMY (ICA, 2016). From a practical perspective, there have been longstanding concerns that the increasing alignment and convergence of other disciplines with cartography is leading to a dilution of cartographic practice and a deskilling of its practitioners (Pickles, 1995). Unfortunately, alterations in educational policy in most parts of the world have meant that pedagogical resources have not been expanded to solidify those practices and skills in cartography: instead novel technologies and contemporary preference for 'quick wins' in superficially achieved competencies have proliferated and, in many cases, have replaced in-depth instruction in cartography.

The terms of reference of the CET recognize the need to develop relevant educational programs presenting agreed and satisfactory learning aims, within the bounds of an established and agreed Body of Knowledge. This paper addresses the concept, nature, development, implementation and maintenance of a BoK, presenting progress so far in its creation.

\section{Disciplinary epistemology}

A Body of Knowledge is essential for presenting the scope, boundaries, and structure of a discipline. Once established, it can be used for a number of purposes primarily for curriculum development in education, but also to confirm relationships between sister disciplines (thus establishing the 'territory' of a branch of learning); to establish expectations in professional practice and specialist skills; to prepare responses to challenges and opportunities in the specific field (including formal research); to create a repository of accepted methods and praxis; and to present a road map to guide both future interdisciplinary collaboration and subject evolution. In addition to such 'internal' rationales, a BoK has an 
outward-looking role in presenting the integration of knowledge, working practices, skills and competencies, and elements of a discipline, to the rest of society (Shoemaker and Mead, 2013).

In order to develop the BoK, some fundamental aspects of knowledge itself must be considered. It is important to consider the nature of knowledge and to examine how subject-specific knowledge is created, compiled and presented. This involves acknowledgement of some general epistemological (the study of the theory of knowledge) approaches, which are varied and can lead to differing methods of systematizing and disseminating a BoK. For ex-ample, there is a view that the only valid knowledge to be stored and applied is that obtained from direct experience. Such an empirical view of knowledge can encourage active, collaborative and exploratory learning, which resonates with contemporary educational practice including problem-based learning and studentcentred class-rooms. The opposite of such socialconstructivist knowledge is a priori, objective knowledge, independent of the knower and his/her location or circumstances (Sfard, 2006).

\subsection{Further considerations of 'knowledge'}

In order to create the BoK and for it to be useful, such polarized views of the nature of knowledge must be recognized, whilst acknowledging that the document created will draw from educational and practical experiences in a wide range of learning environments. Further, the nature of knowledge involves several specific reflections: in cartography (and in most other disciplines), for example, the data handled possesses uncertainty and vagueness, and the methods for and need to efficiently handle such information must be incorporated into the BoK. Further, there is a range of 'troublesome knowledge' - ideas which appear counter-intuitive or difficult to grasp. This is associated with the idea of 'threshold concepts' - the acquisition of knowledge which cannot be 'unlearned' and which, once successfully tackled (thresholds often define 'difficult' material), can be used to build upon for future learning. Knowledge may also be contested and subject to debate. Identifying key threshold concepts could help to form ideal 'stepping stones', milestones and targets in an educational curriculum.

Experience with the creation of formalized Bodies of Knowledge is that it is possible to compile subjectspecific, authoritative, official material into documents which meet the needs of many disciplines, but that relativist, socially constructed, empirically-derived knowledge is much more difficult to incorporate (Fairbairn, forthcoming). Any us-able BoK in cartography needs to present concepts and fundamentals, but should also understand the role of knowledge acquisition by participation.

\subsection{Extensions to disciplinary knowledge for a BoK}

The task of developing a BoK does imply that a formal canon of subject-specific content exists, which can be gathered and structured for the purposes outlined in
Section 2 above. Thus, the content is important, and in a subject like cartography, a significant amount of objective and fact-based material derived from rationalism, will be evident.

However, 'fixed' axioms, concepts and theories, whilst contributing greatly to a discipline's knowledge base, must be supplemented by empirical knowledge in some way, along with specifically identified skills and attitudes. Further, newly emerging techniques and practices, knowledge increments derived from experience, and changes in human approaches to a discipline, each affect every discipline and a BoK must be capable of being receptive to a host of such revisions: the BoK must be regarded as a dynamic document. It is suggested here that construction of a BoK in cartography must incorporate

- the range of technical and applied skills which characterize the science and technology of the subject;

- professional attitudes and operating conventions (including project management, networking, ethics etc.);

- acknowledgement of the impact of complementary and foundational subjects (e.g. maths, IT, creativity);

Many of these 'extensions' to the content of a BoK can be exemplified by looking at other Bodies of Knowledge in other fields of human activity.

\section{Learning from other Bodies of Knowledge}

Several disciplines which are closely related to cartography have developed Bodies of Knowledge which can be profitably examined to assist in determining what a BoK in cartography will look like. In some cases, the $\mathrm{BoK}$ is primarily directed to pedagogy and curriculum development e.g. the Geographic Information Science and Technology (GIST) BoK (Prager, 2012). In other cases, the intention is to list competencies from an employment perspective (Lucena et al., 2008). Reference to other Bodies of Knowledge reveals that there are a number of potential components of, and issues for, a BoK which would be valuable to include within the cartography BoK.

The GIST BoK presents a well-considered and expertly presented set of headings and sections, first published in 2006 (Kemp, 2012). The process of creating this BoK involved a range of organizations, research funding initiatives, task forces and sub-committees, and 'community efforts'. Dominated by educational objectives, the main driver for this BoK development was the expansion of a previously created Core Curriculum: the result is a comprehensive listing and arrangement of 330 topics, organized into 73 units, under 10 separate headings. Each topic is associated with multiple, highly detailed, learning outcomes, ideally presented for classroom delivery, discussion and assessment. The BoK can be accessed in innovative ways through visualization tools, a wiki, a virtual environment portal, and an 'exploratorium' for updating. This is an impressive, 
collaborative effort, currently open to revision, and reaching out to other communities to ensure relevance and effectiveness e.g. through the European AGILE organization (Ahearn et al., 2013).

A BoK for the discipline of land surveying has been developed in a fairly 'low-key' fashion, primarily to address the views of accreditation bodies, and the nature of the surveying profession. It therefore concentrates on the objectives and outcomes of educational provision in, accreditation procedures using, and practical implementations in-formed by, the core concepts of the discipline. Although not prescriptive on delivery details, and not, in practice, widely consulted by professional bodies, commercial and governmental practitioners or educational establishments, the surveying BoK includes an admirable range of specific knowledge, and usefully extends the 'curriculum' metaphor for a BoK. It proposes 'macro-level' (i.e. foundational) material in science and maths, and associated 'micro-level' sub-units, which concentrate on competencies; but it also declares professional 'outcomes' to be met by those following the BoK (Greenfeld, 2010).

Associated with land surveying, the much broader discipline of Civil Engineering is even more subject to professional accreditation. The pre-eminent Civil Engineering Body of Knowledge (ASCE, 2008) presents a three-fold di-vision of engineering practice, allocating 24 broad 'outcomes' to either the 'foundational' category (e.g. mathematics, social sciences), the 'technical' category (e.g. mechanics, design, technical specialization) or a 'professional' heading (e.g. teamwork, lifelong learning). This BoK is also informed by pedagogical theory, as it details 'Levels of Achievement' (knowledge, comprehension, application, analysis, synthesis, evaluation) for each outcome, which are directly based on Bloom's taxonomy of learning domains.

As a competency-driven manifesto, this document embraces knowledge wider than disciplinary-specific educational content. Extending the list-based pedagogic structure, the Civil Engineering BoK presents useful commentaries on involvement of practitioners in the methods of civil engineering and the acquisition of knowledge: there are sections entitled 'Guidance for Students', 'Guidance for Engineer Interns' and 'Paths to Fulfillment', reflecting the wealth of accumulated expertise from the ASCE committee's work.

Commenting on engineering Bodies of Knowledge, Adams et al. (2011) address fundamental issues of engagement and retention of young entrants into the engineering professions: they suggest that a 'multiperspective' approach can help to map a "landscape of multiple ways of knowing, such as technical, organizational, and personal" (p.51). It is suggested that knowledge of engineering should not place technical problem solving at the core, should avoid concentrating only on formal disciplinary knowledge, and not give only superficial attention to professional competencies. Instead, a 'meta-inquiring system' should be implemented to enable transformative knowledge, en- courage innovation by linking research with practice, and encourage pluralism. A recognition of incomplete knowledge, and the role of intuition and experience in dealing with it, is also highlighted. Further, the existence of multiple knowledge paradigms, even in areas of rigorous engineering practice must be recognized: a BoK must re-flect such multi-perspective approaches to knowledge creation and impact.

It seems, therefore, that there is more to a Body of Knowledge than just a list of relevant topics: it must embrace and respond to the whole disciplinary community; it must crystallize the experience and expertise of all practition-ers; it must promote disciplinary excellence, and manage accreditation and quality control; and it must present achievable and tangible outcomes which demonstrate progressive engagement with the discipline. How can such a document be developed for cartography?

\section{Creating the Cartography BoK}

The task of creating a Body of Knowledge for any discipline is not trivial, and there is no one accepted method for collating the material which is incorporated within a BoK. The work of the Commission on Education \& Train-ing has followed a standard consensus-seeking procedure to create a document with agreed scope, content and use.

The Delphi technique uses identified experts to collect and aggregate informed and agreed judgements. A significant amount of consultation is necessary, during the preparation, the actual opinion collection, and the dissemination stages. The main characteristics of the Delphi approach are to rely on the (anonymized) initial views of experts, followed by an iterative process of feedback and discussion (Keeney et al., 2011).

\subsection{Using Delphi to construct the BoK}

For a cartography BoK, the initial consultation needs to address the divergent nature of the discipline. Cartographic activity is the epitome of state-led enterprise, so throughout the world many expert cartographers are employed by government. Those employed in commercial cartography, often developing customized modes of working and gaining advantage by identifying innovative application areas, are likely to offer expertise also. Academic cartographers, and those devoted to education, are responsible for disseminating the fundamentals, and also for ex-tending research, and are consequently interested and able contributors to BoK creation. Due to its widespread applications, cartography has an extensive 'user community', and there are also many associated disciplines with synergistic relationships with the discipline: clearly, any consultation about what constitutes the scope and practice of cartography will require some input from associated disciplines, practitioners and users. One example might be those who work in the 'GLAM' community (Galleries, Libraries, Archives, Museums) who have experience in working with cartographic data, engaging with cartographers to 
help record and disseminate their work, and who utilize cartographic products for their own benefit.

With the 'democratization' of cartography, and the level of interest in mapping being raised in contemporary society with the widespread adoption of cartographic paradigms in a range of human activity, culture, information and societal environments, a further community of people, characterized here as 'volunteer amateurs', are also valuable opinion sources.

The Delphi approach to such opinion-seeking relies on questionnaire survey and/or other methods (e.g. interviews, focus groups, practitioner observation etc.) for obtaining 'content'. The nature of communication, collaboration, repetition, and reporting must be made known to the participants from the start to ensure continued engagement throughout the process, which may be lengthy. The means of scrutiny of the content using statistical pro-cessing or discourse analysis must also be established, although this is unlikely to be complex. The use of summaries to preserve anonymity is expected in the Delphi process, but the reporting of conflicting views and the analysis of disagreements should also be possible.

As a widely-used method for sampling personal opinion, the Delphi method has been employed in BoK creation in other disciplines (Boyd and Amihu, 2014; Moxham et al., 2014), with successfully achieved outcomes of consensus gathering and effective BoK construction.

\section{The look of a Body of Knowledge}

The Commission's work is expected to result in a proposed structure for an approved BoK for cartography. There are several elements which will make up this document, some already highlighted in Section 3 above. The planned BoK needs to present a number of different types of knowledge, and organize them in ways appropriate for a variety of uses. The distinction between core knowledge and decontextualized, complementary knowledge should be made: the former will detail specifically cartographic topics and issues, with 'learning outcomes' presented, whilst the latter will indicate the important effects of engaging with professional and supporting disciplines. Learning goals and 'levels of achievement' can be explicitly presented. Material related to everyday practice in the technical activities of cartography is to be included, and termed 'skills'. Further explanation and clarification of the discipline will be elucidated in the form of 'experience reports' presented from the position of students, researchers, educators, employers, accreditation bodies, and 'amateur', informal practitioners. Such reports will highlight aspects of content and application of the BoK, including identification of 'threshold concepts', methods and practice of 'accreditation', the nature and location of 'boundaries and overlaps' with related disciplines, and interpretations of the 'attitudes' and approaches to the discipline required from its adherents. These include identification of required generic skills, such as communication and team-working abilities. Contested and 'uncertain knowledge' needs to be highlighted also.
Because the viewpoints of those engaged in sister disciplines are important, 'linking knowledge', presenting the nature of cartography as seen from the perspective of related disciplines will be incorporated.

In addition to developing the actual deliverable, the blueprint for a BoK must also present the means whereby it is actually disseminated and used. The educational community, the practitioners, the researchers, the employers and accreditation agencies, and those working in their own disciplines alongside cartographers must have ready ac-cess to the BoK in order to benefit from its summarizing and integrating nature.

\section{Using a Body of Knowledge}

The creation of a BoK is purposeful. It is central to the development of a disciplinary canon, it defines the boundaries (however fuzzy) between one discipline and another, and it is an attempt to unify (but not necessarily to standardize) the discipline. Current examples of BoKs show significant variation and consequently there appears to be varying utility of such documents.

The use of a BoK to help develop a 'core curriculum' is central to the GIST experience, although those involved in the GIST BoK revision do stress that its intended use is not to be prescriptive in curriculum design (Prager, 2012). The expectation for a cartography BoK is that it can be used to construct developmental and progressive syllabi in educational applications (Fairbairn, forthcoming). Although such focused curriculum development is a positive out-come for the BoK, it should be considered as a more widely applicable document.

From a general perspective of cartography, the establishment or confirmation of disciplinary territory would be advantageous, for both 'internal' purposes, but also to present the integration of knowledge, working practices, skills and competencies, and elements of cartography, to the rest of society. Such an outcome would also confirm relationships with sister disciplines.

The reporting of both research and practice within the BoK should encourage a closer link between these two major elements of cartographic activity. In general, a comprehensive BoK should help in identifying challenges and opportunities in the field of cartography, and allow for, respectively, responses and adoption, within the paradigms of cartographic practice. The paradigms, accepted methods and practices of cartography will be presented in the BoK, which should stress the multiple knowledge approaches to the discipline which exist. 'What is known' will be recorded, as will 'what is not': incompleteness and incompatibilities in knowledge will encourage innovation, use of intuition, and creativity, all hallmarks of contemporary cartography.

Such cartographic activity, as reported in the BoK, forms the basis for accreditation and application of professional standards. Assessing workplace-readiness, recognizing acquired skills and experience, and setting levels of professional competence, are all important aspects in establishing a discipline's place in the real world. The assessment of competence in professional specialties can 
be formalized with reference to a BoK which has been created to cover both disciplinary knowledge and skills sets. Once an authoritative BoK has been devised, it can be used as a reference document for accreditation or possibly as a regulatory instrument. Using the BoK in this manner will al-low for assessment of shortfalls in competencies, engagement and retention of enthusiastic and qualified professionals, identification of skills gaps, and support of 'networks of expertise' (Edwards, 2005).

Regular surveys of skill shortages, employer needs and graduate opportunities, often undertaken by governmental educational agencies, employers trade organizations, and employment consultants, have a valuable role to play in the important task of maintaining the BoK. Wallentin et al. (2015) detail some of the practical ways by which revision of the GIST BoK have been informed by such initiatives.

One final example of BoK usage is exemplified by Moellering $(2012,2015)$ who uses the BoK concept to reflect on the immediate past history of the discipline, noting its contribution to, and derivations from, the wider field of spatial science. In doing so, he explores the definition and the boundaries of the subject of cartography, and also reflects on the published Research Agenda for cartography and GIScience, which is predicated on a well-defined discipline, with bounds which assist in promoting specific cartographic research and highlighting areas of prospective inter-disciplinary research. This further driver towards the creation of a cartography BoK is indicative of the value of such a wellconstructed and informed document.

\section{References}

Adams, R., Evangelou, D., English, L., De Figueiredo, A., Mousoulides, N., Pawley, A., Schifellite, C., Stevens, R., Svinicki, M., Trenor, J., and Wilson, D. (2011). Multiple Perspectives on Engaging Future Engineers, Journal of Engineering Education, 100 (1), 48-88.

Ahearn, S., Icke, I., Datta, R., DeMers, M., Plewe, B., and Skupin, A. (2013). Re-engineering the GIS\&T Body of Knowledge, Inter-national Journal of Geographical Information Science, 27(11), 2227-2245.

ASCE (2008). Civil Engineering Body of Knowledge for the 21st Century. Reston, VA: American Society of Civil Engineers.

Boyd, D. and Amidu, A.-R. (2014). Developing a practice-based body of real estate knowledge: a Delphi study. Journal of Real Es-tate Practice and Education, 17(2), 139-167.

Buchroithner, M. and Gartner, G. (2013). The New Face of Cartography. GIM International, June 2013, 22-27.

Edwards, A. (2005). Relational agency: Learning to be a resourceful practitioner. International Journal of Educational Research

43(3), 168-182
Fairbairn, D. (forthcoming). A blueprint for a 'Body of Knowledge': an exercise in disciplinary epistemology. Journal of Geography in Higher Education.

Greenfeld, J. (2010). Surveying Body of Knowledge, presented at FIG Congress 2010, Facing the Challenges - Building the Capaci-ty, Sydney, Australia, April 2010

ICA (2016). International Map Year 2015-16. http://mapyear.org. Accessed 20 Nov 2016.

Keeney, S., Hasson, F. and McKenna, H. (2011). The Delphi Technique in Nursing and Health Research, Chichester: Wiley.

Lucena, J., Downey, G., Jesiek, B. and Elber, S. (2008). Competencies Beyond Countries: The Re-Organization of Engineering Educa-tion in the United States, Europe, and Latin America, Journal of Engineering Education, 97(4), 433-447.

Moellering, H. (2012). The International Cartographic Association Research Agenda: Review, Perspectives, Comments and Recom-mendations. Cartography and Geographic Information Science, 39(1), 61-66.

Moellering, H. (2015). Contributions of analytical cartography to GIScience, in Proceedings of the 27th International Cartographic Conference, Rio de Janeiro, Brazil.

Moxham, B., Plaisant, O., Smith, C., Pawlina, W. and McHanwell, S. (2014). An approach toward the development of core syllabuses for the anatomical sciences. Anatomical Sciences Education, 7, 302-311.

Pickles, J. (1995). Ground Truth. New York: Guilford Press.

Prager, S. (2012). Using the GIS\&T Body of Knowledge for curriculum design: different design for different contexts. Chapter 5 (63-79) in Unwin, D., Foote, K., Tate, N. and DiBiase, D. (eds). Teaching Geographic Information Science and Technology in Higher Education. London: Wiley.

Sfard, A. (1998) On Two Metaphors for Learning and the Dangers of Choosing Just One, Educational Researcher, 27(2), 4-13.

Shoemaker, D. and Mead, N. (2013). Building a Body of Knowledge for ICT Supply Chain Risk Management, Crosstalk: the Journal of Defense Software Engineering, 26(2), 24-28.

Wallentin, G., Hofer, B. and Traun, C. (2015). Assessment of Workforce Demands to Shape GIS\&T Education. Transactions in GIS, 19, 439-454. 